\title{
Evaluation of two test methods for the strain measurement of interior paints
}

\author{
Aleksandar Milkov Radoevski ${ }^{1}$, Michael Höflinger ${ }^{2}$, Edmund Spitzenberger ${ }^{3}$, \\ Razmik-Roger Ghanbari ${ }^{1}$, Andreas Kolbitsch ${ }^{1}$
}

\author{
${ }^{1}$ Institute for Building Construction and Technology, Building Construction and Maintenance E206-04,Vienna University \\ of Technology, Karlsplatz, 13/206-04, 1040, Vienna, Austria. \\ ${ }^{2}$ Dr. PECH Ziviltechniker GmbH - Ziviltechnikergesellschaft für Bauingenieurwesen, Johann - Strauß-Gasse, 32/11, 1040 \\ Vienna, Austria. \\ ${ }^{3}$ Department for Building and Design, University of Applied Sciences Vienna, FH Campus Wien Favoritenstrasse, 226, \\ 1100, Vienna, Austria. \\ e-mail: a.radoevski@gmx.at, roger.ghanbari@yahoo.com, andreas.kolbitsch@tuwien.ac.at, hoeflinger@zt-pech.at, \\ edmund.spitzenberger@fh-campuswien.ac.at
}

\begin{abstract}
The appearance of structural cracks is nothing unusual neither in old nor in new buildings. The causes of these cracks range from improper selection and use of materials to faulty design, and can have serious consequences. In buildings in which the structural integrity is not endangered, cracking, especially in interior spaces, constitutes a significant impairment of the building's serviceability. The repair costs for these cracks are often considerable. Fortunately, a cost-effective and lasting solution to this cracking problem can be found in the use of more elastic interior paints. In order to utilize this solution, it is essential to know the elastic properties of the paint; however, manufacturers often fail to provide adequate information in this respect. In addition, the European market lacks standardized procedures for quantitatively determining the elasticity of paint. By combining two independent mechanical test methods, it is attempted to obtain a quantitative determination of the strain of interior paints. The suitability and relevance of the test methods used is discussed on the basis of the results obtained. The tests used are the classical tensile test in accordance with DIN EN ISO 6892-1 and a modified 3-point bending test based on DIN EN ISO 178. In order to determine the strain, optical deformation analysis by means of digital image correlation (DIC) is used for both test methods.
\end{abstract}

Keywords: Interior paint, Strain, Cracks, Tensile test, 3-point bending test

\section{INTRODUCTION}

Structural cracks arise in both old as well as new buildings due to various factors and influences. Due to high cost and technical complexity the production and/or the preservation of absolutely crack-free constructions is not implemented in practice. First and foremost, crack formation impairs the serviceability and durability of the structure; furthermore, even its stability could be at risk [1].

An impairment of the serviceability in the interior of a building is starting usually as soon as the cracks on the component surface are apprehensible to the naked eye. The perception of the cracks is commonly defined by their width [2]. Structural cracks up to $0.2 \mathrm{~mm}$ are defined as hairline cracks [1], and in accordance with DIN 18550-1 [3] they do not present any optical or technical deficiencies.

For structures whose stability is at risk due to static problems visible cracking is essential, as this cracking can be a sign for potential danger to life and limb [2]. Yet there are many other cases as well, in which the visible cracking occurs mainly due to construction physics [4]. Examples thereof include specific cracks in the butt joints in drywall constructions due to thermal or hygric dimensional change [5], or cracks in plasters and fillers with insufficient adhesion to the substrate, or cracks due to the application of plasters and fillers to substrates with greatly varying shrinkage rates (extreme case: gypsum plaster on lightweight concrete) [6]. In these cases the cracks arise due to tensile stresses on the component surface and they are not related to the stability of the structure. Nevertheless, this cracking is undesirable, since it can represent a significant impairment of serviceability, especially in the interior. Moreover, its reparation is time-consuming and expen- 
sive [7]. A possible solution to this problem is the use of a stretchable interior coating, which can successfully bridge such cracks in the coating substrate.

In many cases, however, the selection of the correct interior coating with the desired elasticity proves to be difficult, as many manufacturers give insufficient or no information about the elasticity of their products. The prime reason for the missing information might be the fact that there is currently no standardized method in the European Union for determining the extensibility or crack-bridging capacity of interior coatings. On the European level there are only standardized test methods for determining crack bridging properties of coating materials and coating systems for exterior masonry and concrete (DIN EN 1062-7 [8]), as well as polymer modified bituminous thick coatings for waterproofing (DIN EN 15812 [9]). However, these methods are not suitable for interior coatings, as these coatings are so delicate that they cannot withstand the load of the testing equipment. The testing equipment in both standards was developed for coatings with an average thickness of about $3 \mathrm{~mm}$ and was dimensioned accordingly. In contrast, the thickness of a typical interior coating is only about $0.3 \mathrm{~mm}$. Furthermore, the above mentioned test methods do not provide accurate measurements, but only a categorization of crack-bridging capability. For example in a static crack-bridging test, given in DIN EN 1062-7, the crack-bridging capability of a coating has been examined, as a coated specimen undergoes a defined deformation. Depending on whether the applied coating withstands this deformation with or without cracks, the class of the crack-bridging capability of the coating has been specified.

In the literature different test methods and approaches for determining the extensibility of thin coatings, like interior paints, are presented. Tan et al. [10] describes a method for examining the elasticity of pipeline coatings, based on the 3-point bending test, in which the coating is applied on metal plates. To initiate an extension of the applied coating, these plates are bending by the setup of the 3-point bending test, so that the coated side becomes convex. The extension of the coating is determined by strain gauges mounted on the metal plate. To examine the elasticity of highly filled epoxy coatings used for corrosion protection on ships, Wray et al. [11] produced freestanding (without carrier material) dogbone specimens for tensile tests in accordance with ISO 527-1 [12]. The preparation of these specimens was carried out by applying the coating on PTFE coated glass, which enables the separation of the coating from the surface after the drying process without causing damages to the coating layer. However the application of these methods to interior coatings is in many cases not possible, due to their properties, such as the specific drying behavior and the relatively low strength. Therefore, the development of new or the adaption of existing test methods is needed.

In this study an attempt is made to quantitatively evaluate the extensibility of selected interior coatings with the help of two mechanical test methods. The first method basically corresponds to the classical tensile test for metallic materials according to DIN EN ISO 6892-1 [13] with flat tensile specimens in accordance with DIN EN 50125 [14]. The second method involves a modification of the 3-point bending test according to DIN EN ISO 178 [15], in which a layer of interior coating applied to the bottom side of a bending beam is subjected to tensile stress through the generated bending process (an Austrian patent application (A 50471/2018) for this method was filed on 12 June 2018). In both the tensile test and the modified 3-point bending test, the strains are detected by optical deformation analysis using digital image correlation (DIC).

\section{OVERVIEW OF THE TESTED COATINGS}

A total of 10 interior coatings by different manufacturers were selected for the examination. All of them are water-based but differ in their composition (Table 1) as well as their properties and qualities (Table 2). For reasons of data protection, the names of the manufacturers are replaced by uppercase letters in alphabetical order, and the products are listed as "Standard" or "Premium" according to their quality as specified by the manufacturer. The Latex coating [16,17] will further be referred to as "Latex".

Table 1: Ingredients of the selected interior coatings for the material examination according to the manufacturer.

\begin{tabular}{l|c|c|c|c}
\hline COATING & BINDER & FILLERS & PIGMENTS & PRESERVATIVES \\
\hline $\mathrm{A}$ & (-) copolymer & $\begin{array}{c}\text { dolomite } \\
\text { talc }\end{array}$ & $\begin{array}{c}\text { kaolin } \\
\text { titanium dioxide }\end{array}$ & $\begin{array}{c}\text { benzisothiazolinone (BIT) } \\
\text { methylisothiazolinone (MIT) }\end{array}$ \\
\hline $\mathrm{B}$ & $\begin{array}{c}\text { polyvinyl acetate } \\
\text { copolymer }\end{array}$ & $\begin{array}{c}\text { calcium carbonate } \\
\text { silicate }\end{array}$ & titanium dioxide & $\begin{array}{c}\text { benzisothiazolinone (BIT) } \\
\text { methylisothiazolinone (MIT) }\end{array}$ \\
\hline $\mathrm{C}$ & $\begin{array}{c}\text { styrene acrylate } \\
\text { copolymer }\end{array}$ & $\begin{array}{c}\text { calcium carbonate } \\
\text { silicate }\end{array}$ & $\begin{array}{c}\text { inorg./org. colored pigments } \\
\text { titanium dioxide }\end{array}$ & $\begin{array}{c}\text { benzisothiazolinone (BIT) } \\
\text { methylisothiazolinone (MIT) }\end{array}$ \\
\hline D-Standard & $\mathrm{n} / \mathrm{a}$ & $\mathrm{n} / \mathrm{a}$ & $\begin{array}{c}\text { benzisothiazolinone (BIT) } \\
\text { methylchloroisothiazolinone } \\
\text { (MCI) }\end{array}$ \\
\hline
\end{tabular}




\begin{tabular}{|c|c|c|c|c|}
\hline D-Premium & $\begin{array}{l}\text { vinyl acetate } \\
\text { copolymer }\end{array}$ & silicate & titanium dioxide & $\begin{array}{l}\text { benzisothiazolinone (BIT) } \\
\text { methylchloroisothiazolinone } \\
\text { (MCI) } \\
\text { methylisothiazolinone (MIT) }\end{array}$ \\
\hline D-Latex & $\begin{array}{l}\text { vinyl acetate } \\
\text { copolymer }\end{array}$ & $\mathrm{n} / \mathrm{a}$ & $\mathrm{n} / \mathrm{a}$ & $\begin{array}{l}\text { benzisothiazolinone (BIT) } \\
\text { methylchloroisothiazolinone } \\
\text { (MCI) } \\
\text { methylisothiazolinone (MIT) }\end{array}$ \\
\hline E-Standard & $\begin{array}{l}\text { acrylate copolymer } \\
\text { vinyl acetate } \\
\text { copolymer }\end{array}$ & $\begin{array}{l}\text { carbonate } \\
\text { silicate }\end{array}$ & titanium dioxide & $\begin{array}{l}\text { benzisothiazolinone (BIT) } \\
\text { methylchloroisothiazolinone } \\
\text { (MCI) } \\
\text { methylisothiazolinone (MIT) }\end{array}$ \\
\hline E-Premium & $\begin{array}{l}\text { acrylate copolymer } \\
\text { vinyl acetate } \\
\text { copolymer }\end{array}$ & $\begin{array}{l}\text { carbonate } \\
\text { silicate }\end{array}$ & titanium dioxide & $\begin{array}{l}\text { benzisothiazolinone (BIT) } \\
\text { methylchloroisothiazolinone } \\
\text { (MCI) } \\
\text { methylisothiazolinone (MIT) }\end{array}$ \\
\hline F-Standard & $\begin{array}{l}\text { vinyl acetate } \\
\text { copolymer }\end{array}$ & $\begin{array}{c}\text { aluminium silicate } \\
\text { calcium carbonate } \\
\text { diatomaceous earth } \\
\text { organic fillers } \\
\end{array}$ & $\begin{array}{c}\text { kaolin } \\
\text { titanium dioxide }\end{array}$ & $\mathrm{n} / \mathrm{a}$ \\
\hline F-Premium & $\begin{array}{l}\text { acrylate copolymer } \\
\text { silicone resin }\end{array}$ & $\begin{array}{l}\text { calcium carbonate } \\
\text { diatomaceous earth }\end{array}$ & titanium dioxide & octylisothiazolinone (OIT) \\
\hline
\end{tabular}

Table 2: Properties of the selected interior coatings for the material examination according to the manufacturer.

\begin{tabular}{|c|c|c|c|}
\hline \multirow[t]{2}{*}{ COATING } & \multicolumn{2}{|c|}{$\begin{array}{c}\text { PROPERTIES ACC. TO } \\
\text { DIN EN } 13300[18]\end{array}$} & \multirow[t]{2}{*}{ GENERAL PROPERTIES } \\
\hline & Wet scrub resistance ${ }^{1}$ & Contrast ratio ${ }^{2}$ & \\
\hline A & $\mathrm{n} / \mathrm{a}$ & $\mathrm{n} / \mathrm{a}$ & low-emission \\
\hline B & Class 2 & Class 1 & diffusible, adhesive \\
\hline $\mathrm{C}$ & Class 3 & Class 2 & diffusible, low-emission \\
\hline D-Standard & Class 4 & Class 2 & diffusible \\
\hline D-Premium & Class 2 & Class 1 & diffusible \\
\hline D-Latex & Class 2 & Class 3 & cleanable, elastic \\
\hline E-Standard & Class 2 & Class 1 & low-emission, solvent-free \\
\hline E-Premium & $\mathrm{n} / \mathrm{a}$ & $\mathrm{n} / \mathrm{a}$ & diffusible, elastic \\
\hline F-Standard & Class 2 & Class 1 & diffusible, solvent-free \\
\hline F-Premium & Class 1 & Class 3 & diffusible, solvent-free \\
\hline
\end{tabular}

${ }^{1}$ The resistance to repeated cleaning classified according to coating thickness loss as follows: Class 1: $<5 \mu \mathrm{m}$ at 200 scrubs; Class 2: 5 - $20 \mu \mathrm{m}$ at 200 scrubs; Class 3: $20-70 \mu \mathrm{m}$ at 200 scrubs; Class 4: $<70 \mu \mathrm{m}$ at 40 scrubs; Class 5: $\geq 70 \mu \mathrm{m}$ at 40 scrubs; ${ }^{2}$ The comparison of the coating with a standardized (white) surface in percent classified as follows: Class 1: $\geq$ 99.5; Class 2: $\geq 98$ and $<99.5$; Class 3: $\geq 95$ and $<98$; Class $4:<95$

\section{STRAIN MEASUREMENT ON COATED TENSILE SPECIMENS}

\subsection{Experimental program and test specimen}

After several preliminary tests the production of crack-free specimens made entirely of interior coating proved to be practically unachievable. The reason for this was especially the drying behaviour of the interior coating, which repeatedly led to the formation of cracks (comparable to drying shrinkage cracks [19]), mostly combined with a pronounced deformation of the specimen. In order to solve this problem a carrier material was used for the preparation of the samples, on which the coating was applied. The requirements concerning the carrier material for the tensile specimens were on 
the one hand sufficient extensibility, which had to be higher than that of the coating, and on the other hand appropriate absorbency, which ensures the adhesion of the coating to the carrier material and its proper drying. After performing the necessary material research, a 1-mm-thick grey board (GK) [20,21] with a weight per unit area of approx. $700 \mathrm{~g} / \mathrm{m}^{2}(\mathrm{acc}$. to the manufacturer) and an extensibility of approx. 32\% (measured) was selected as carrier material for the tensile samples. From this carrier material 10 samples were prepared for each of the 10 indoor coatings. The shape and the designation of the tensile specimens conform with the requirements of DIN EN 50125 [14] for flat tensile specimens "Form E", but the dimensions were adjusted to the purpose of the experiment (Figure 1a).
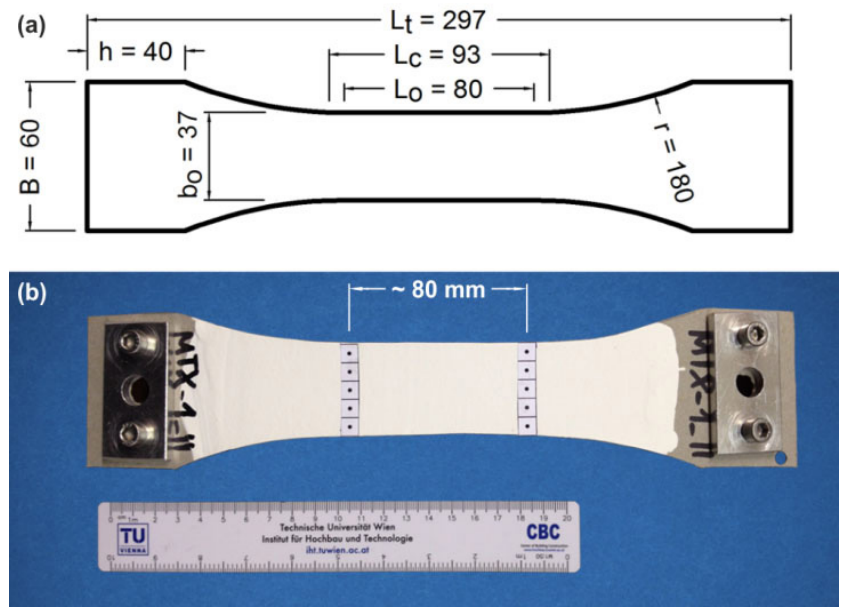

Figure 1: a) Shape and dimensions ( $\mathrm{mm}$ ) of a tensile test specimen; b) ready for testing tensile specimen with point pattern and clamping fixture.

In order to achieve the smoothest and most uniform layer of coating possible on the carrier material, a template was used. Thus, a constant layer of the wet interior coating with a thickness of $0.70 \mathrm{~mm}$ was produced on all test specimens. The drying took place in a climate chamber at $21{ }^{\circ} \mathrm{C}$ and $50 \pm 3 \%$ relative humidity according to the regulations of DIN EN 23270 [22] $\left(23 \pm 2{ }^{\circ} \mathrm{C}\right.$ and $\left.50 \pm 5 \% \mathrm{RH}\right)$. The drying time was about 48 hours, and the thickness of the coating in dried condition (three measure points per sample) is shown in Table 3. Due to dehydration the layer thickness was reduced to an average of about $65 \%$. Fig. $1 \mathrm{~b}$ shows a prepared tensile test sample along with the applied point pattern for the optical deformation analysis digital image correlation (DIC) and a clamping fixture for the testing machine.

Table 3: Thickness of the dried coatings applied to the tensile specimens in $\mathrm{mm}$.

\begin{tabular}{l|c|l|l|l}
\hline COATING & AVERAGE & STD & MIN & MAX \\
\hline $\mathrm{A}$ & 0.19 & 0.03 & 0.13 & 0.23 \\
\hline $\mathrm{B}$ & 0.29 & 0.03 & 0.22 & 0.33 \\
\hline $\mathrm{C}$ & 0.30 & 0.03 & 0.25 & 0.34 \\
\hline D-Standard & 0.30 & 0.03 & 0.25 & 0.34 \\
\hline D-Premium & 0.32 & 0.02 & 0.26 & 0.35 \\
\hline D-Latex & 0.15 & 0.02 & 0.12 & 0.18 \\
\hline E-Standard & 0.22 & 0.03 & 0.16 & 0.29 \\
\hline E-Premium & 0.23 & 0.02 & 0.19 & 0.26 \\
\hline F-Standard & 0.22 & 0.02 & 0.19 & 0.26 \\
\hline F-Premium & 0.19 & 0.02 & 0.15 & 0.22 \\
\hline
\end{tabular}

\subsection{Experimental procedure and measurement equipment}

The tensile tests were performed on a universal tensile and compression testing machine made by INSTRON, model 4206, with a load capacity of $150 \mathrm{kN}$. The tests were, in contrast to DIN EN ISO 6892-1 [10] for tensile tests, not force controlled but displacement controlled with a rate of $0.4 \mathrm{~mm} / \mathrm{min}$. Preliminary tests showed that for a stable crack propagation, the 
displacement control offers advantages over the force control, especially for the purpose of the test evaluation. Furthermore, the displacement control had no significant influence on the deformation behaviour of the tested coatings due to their quasibrittle material behaviour in dry condition. The setup of the used tension test for strain measurement of interior paints is shown in Fig. 2.

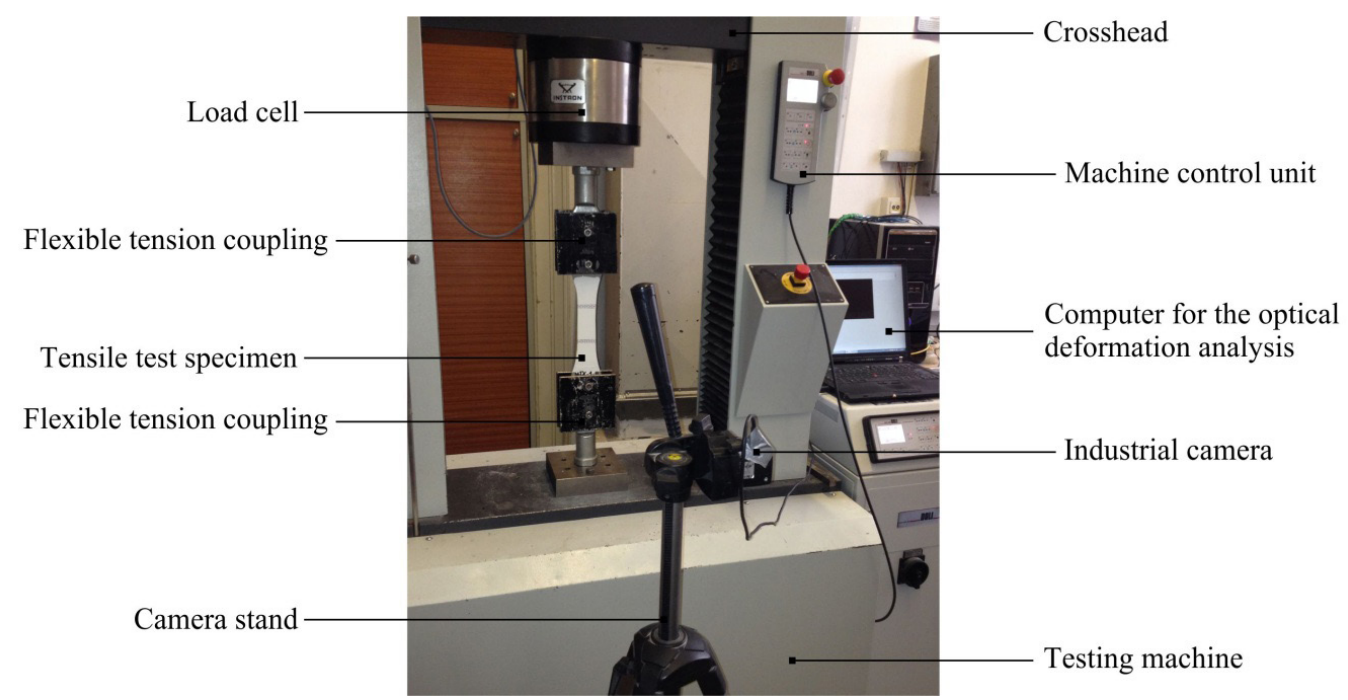

Figure 2: Setup of the tensile test for strain measurements of interior paints.

For the purpose of the optical deformation analysis, an industrial camera of the brand IDS IMAGINGDEVELOPMENT SYSTEMS GMBH, model UEye ${ }^{\circledR}$ UI-1220LE-M-GL was used. During the test, the camera took one picture every $0.5 \mathrm{~s}$ (frame rate $=2 \mathrm{fps}$ ) from the observed area of the tensile test specimen (Fig. 3). These recordings were evaluated with help of an own developed measurement software at the Vienna University of Technology, which determined by means of DIC [23] the coordinates of selected points of the point pattern at the time of each recording. The used measurement software and the industrial camera formed in this way a kind of a video extensometer for the measurement of the specimen's strain. By pairing the recorded images with the force measurements of the testing machine, a tracking of the crack formation with the correlated load curve could be provided for the purpose of the test evaluation. Each test ended when the specimen failed. An example of the crack formation in the observed area of a coated tensile test specimen in the course of a test is shown in Fig. 3.

(a)

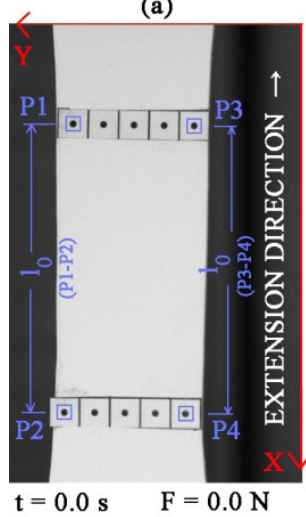

(b)

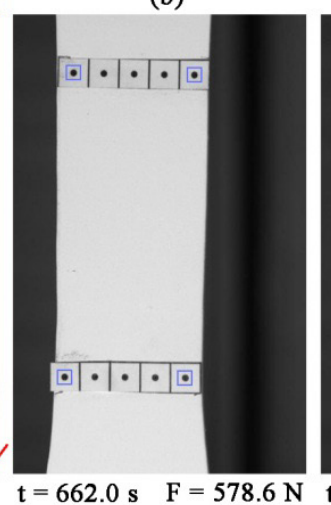

(c)

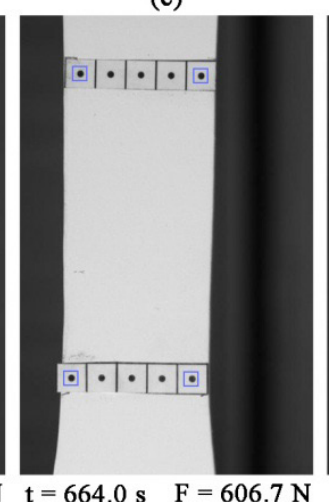

(d)

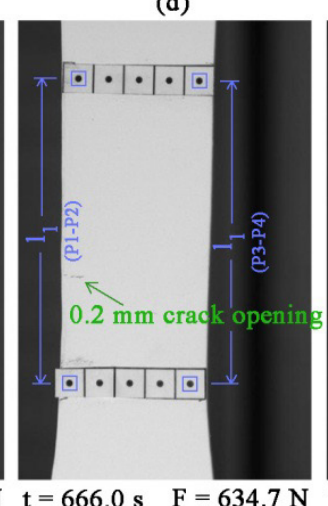

(e)

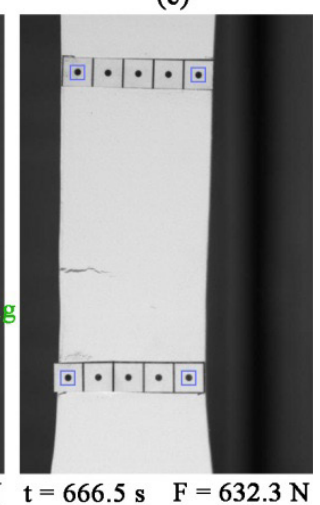

Figure 3: Crack formation in the observed area of a coated tensile specimen in 5 stages (a-e).

Relevant for the optical deformation analysis were only the endpoints "P1", "P2", "P3" and "P4" of the applied point pattern (Fig. 3a). An evaluation of the coordinates of all measuring points was not necessary, as in the measuring range of a tensile specimen (area with constant cross-section) the extension over the entire cross-section of the sample is equal. During the experiment the XY coordinates of the selected 4 points were recorded by the measurement software for 
each taken image. On the basis of the recorded coordinates the distances "P1-P2" and "P3-P4" at the beginning $\left(l_{0}\right)$ and at the end $\left(l_{l}\right)$ of the stretching process (Fig. 3a and 3d) were calculated. As a criterion for the end of the stretching process a crack opening of about $0.2 \mathrm{~mm}$ (hairline crack) in the tested coating was defined. This criterion was implemented, since cracks with opening under $0.2 \mathrm{~mm}$ are not considered as an optical or technical deficiency according to DIN 18550-1 [3].

$$
\varepsilon_{(P 1-P 2)}=\frac{l_{1(P 1-P 2)}-l_{0(P 1-P 2)}}{l_{0(P 1-P 2)}} \cdot 1000 \quad \text { or } \quad \varepsilon_{(P 3-P 4)}=\frac{l_{1(P 3-P 4)}-l_{0(P 3-P 4)}}{l_{0(P 3-P 4)}} \cdot 1000[\% 0]
$$

Depending on whether cracking occurred on the left or on the right side of the specimen, the calculation of the strain was based on the change of the distance "P1-P2" (left) and "P3-P4" (right) according to Eq. (1). In case of equally distributed cracking over the specimen the average of the both calculated strains $\varepsilon_{(P I-P 2)}$ and $\varepsilon_{(P 3-P 4)}$ were taken. This was also the usual case in this study.

\subsection{Results}

After the completion of all tensile tests, the recorded data of the optical deformation analysis were evaluated by the digital image correlation, and the maximal strain up to the formation of hairline cracks was determined. For each coating the strain was calculated as a mean value of all tested specimens, and represented in the bar chart in Fig. 4. In addition, the standard deviation is shown as an error bar, and the number of the tested specimens for each coating is given at the bottom of the chart.

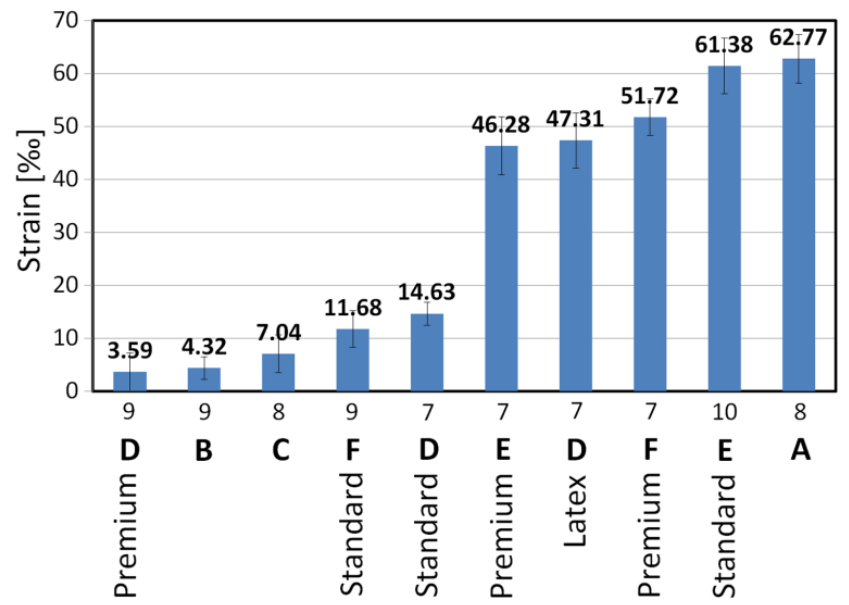

Figure 4: Maximal strain of the interior coatings according to the tension tests in \%o.

Considering the results presented in Fig. 4, it must be noted that in most cases the determined maximal strains do not correlate with the qualitative labels assigned to different coatings produced by the same manufacturer. At this point, it must also be noted that the coatings' quality labels do not explicitly refer to their ductility. Nevertheless, the quality labels are considered as a rough guide in evaluating the results of this study. Examples for this discrepancy are the coatings by manufacturer "D": the "Premium" version is the coating tolerating the lowest strain up to hairline crack, while the "Standard" version had a much higher test result. The coatings by manufacturer "E" show similar results. Again the "Premium" version is by far less stretchable than the "Standard" version. Only with manufacturer "F" the measured strain is in accordance with the products' quality labels. Furthermore, the score of the coating "Latex" is to mention, which is only the fourth best result. Due to its well-known high extensibility [24, 25], the "Latex" coating was used as a reference dimension for the most ductile of all tested coatings in this study.

\section{STRAIN MEASUREMENT ON COATED BENDING BEAMS}

The test method used for these tests is based on the 3-point bending test according to DIN EN ISO 178 [15]. Unlike the standard test, in which the determination of the bending strength is pivotal, these tests focus on the strain measurement of the tested material. The setup of the 3-point bending test serves primarily to produce an extension of the tested specimen, which can be evaluated by optical deformation analysis.

A patent on the setup of the test methods used was filed on 12 June 2018 at the Austrian Patent Office with the application number A 50471/2018 and the title "Biegebalken-Dehnmessverfahren sowie Prüfaufbau zur Durchführung eines solchen Dehnmessverfahrens". 


\subsection{Experimental program and test specimen}

Due to the reasons mentioned in chapter 3.1, the preparation of the specimens for the bending tests also required a carrier material on which the coating can be applied. On the one hand, this carrier material has to be able to obtain the necessary absorbency for the coating, and on the other hand, it would make the production of the bending beams possible, which are needed for the applied test method (Fig. 5). Furthermore, the bending beams need to have sufficient bending stiffness, so that their own weight does not cause bending deformations before the test procedure. This was important to prevent any distortion of the measured strain by pre-deformations. After considering all these requirements, cement bonded particle boards (CBPB) made by CETRIS ${ }^{\circledR}$ type BASIC with the thickness of $24 \mathrm{~mm}$ and weight per unit area of $32.4 \mathrm{~kg} / \mathrm{m}^{2}$ were selected as an optimal carrier material for the bending tests. These boards have similar absorbency to a mineral plaster and have sufficient strength as well as good workability to suit the purpose of the sample preparation. According to the manufacturer, the composition of the boards consists of $63 \%$ wood fibres, $25 \%$ cement, $10 \%$ water and $2 \%$ hydration additives [26].
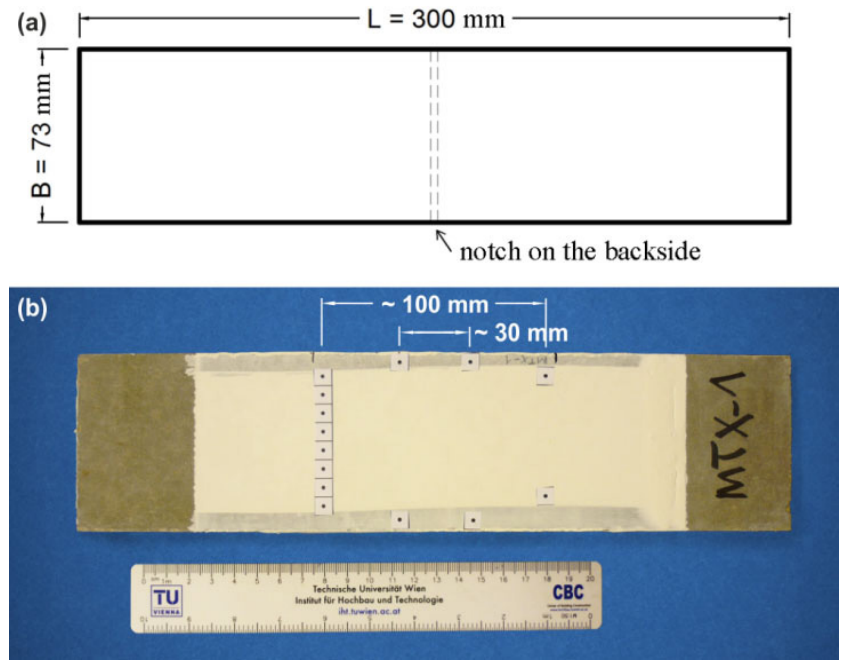

Figure 5: a Shape and dimensions of a bending beam; $\mathbf{b}$ bending beam ready for testing with point pattern.

In contrast to the tensile tests, the number of samples per coating variation was increased to 13 in the bending tests, in order to compensate for possible failures in the experimental procedure. For setting the sample's shape and size (Fig. 5a), the specifications of DIN EN ISO 178 [15] were adapted to the dimensions of the tensile specimens.

Table 4: Thickness of the dried coating applied on the bending beams in $\mathrm{mm}$.

\begin{tabular}{c|c|c|c|c}
\hline COATING & AVERAGE & STD & MIN & MAX \\
\hline A & 0.24 & 0.16 & 0.10 & 0.68 \\
\hline B & 0.26 & 0.11 & 0.08 & 0.45 \\
\hline C & 0.22 & 0.13 & 0.03 & 0.46 \\
\hline D-Standard & 0.19 & 0.07 & 0.09 & 0.36 \\
\hline D-Premium & 0.28 & 0.14 & 0.11 & 0.58 \\
\hline D-Latex & 0.25 & 0.11 & 0.08 & 0.49 \\
\hline E-Standard & 0.21 & 0.09 & 0.12 & 0.41 \\
\hline E-Premium & 0.21 & 0.13 & 0.06 & 0.59 \\
\hline F-Standard & 0.22 & 0.08 & 0.08 & 0.37 \\
\hline F-Premium & 0.25 & 0.12 & 0.10 & 0.54 \\
\hline
\end{tabular}

The preparation of the samples was performed in several individual steps. In the first step, bending beams with the dimensions shown in Fig. 5a were cut out of the cement bonded particle boards. Next, an approx. 3 mm wide notch was cut in the back side of each sample. This notch ran centrally across the beam and was up to half of the beam thickness (approx. $12 \mathrm{~mm}$ ). Its purpose was to concentrate the extension deformations during the testing process to a narrower area on the 
front side of the beam, allowing a more precise recording by the industrial camera and thus, increased accuracy in the test evaluation. In the next step, the bending beams were conditioned in a climate chamber, in order for all samples to obtain the same material moisture of about $14 \pm 1 \%$. Furthermore, as in the tensile tests, the coating was applied by using a template, which ensured the application of a layer with a constant thickness of $0.4 \mathrm{~mm}$. While drying, the coating's thickness was reduced on average by $42 \%$ in approx. 48 hours. As with the tensile tests specimens, the drying process was performed in a climate chamber at $21{ }^{\circ} \mathrm{C}$ and $50 \pm 3 \%$ relative humidity. Table 4 shows the coating's thickness in dried state (three measuring points per sample), which roughly corresponds to the one of the tensile specimens (see Table 3). In the final step of the sample preparation, the point pattern for optical deformation analysis was applied to the dry sample surface in the arrangement shown in Fig. 5 b.

\subsection{Experimental procedure and measurement equipment}

The bending tests were performed displacement controlled on the INSTRON testing machine, like the tensile tests. The test speed was $0.3 \mathrm{~mm} / \mathrm{min}$ and related to the vertical movement of the crosshead of the testing machine. The instrumentation and the frame rate of $2 \mathrm{fps}$ of the optical deformation analysis also correspond to the setup of the tensile tests. For the bending tests, however, the deformation mechanism was essential, after which the stretching process was initiated in the coating to be tested. This was done by the bending deformation of the bending beam, which was caused by the pressing force $F$ of the machine during the test.

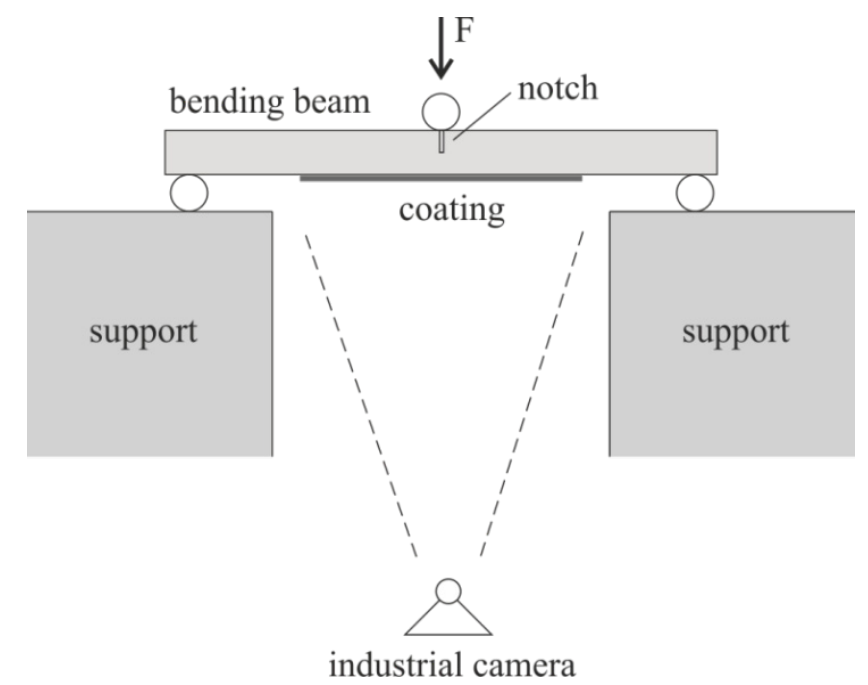

Figure 6: Schematic illustration of the innovative bending test for strain measurements of interior paints.

The bending beam was positioned in the test equipment (Fig. 6) so that the applied coating was on that side of the beam, on which later, as a result of the induced bending deformation, tensile stresses arose. Since the bending beams consisted of cement bonded particle boards in which the compressive strength is a multiple of the tensile strength (acc. to the manufacturer), these tensile stresses led to the desired extension on this side of the beam. Fig. 6 schematically shows the setup of the test method used. 
(a)

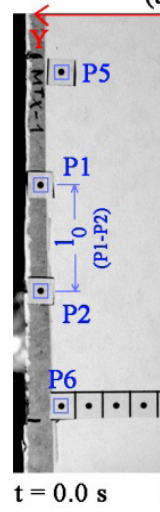

(b)

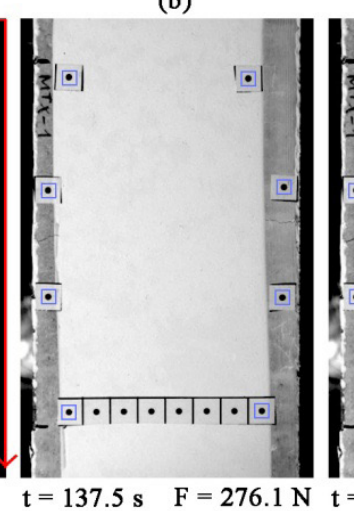

(c)

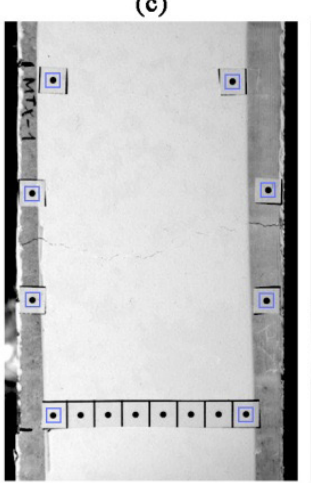

(d)

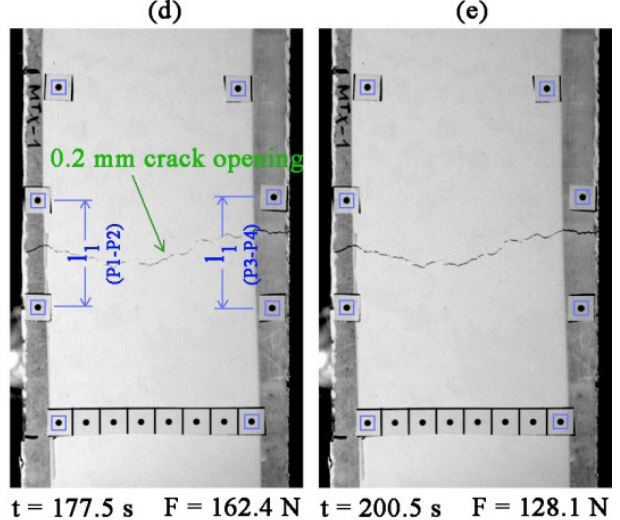

Figure 7: Crack formation on the observed area of a coated bending beam in 5 stages (a-e).

The strain achieved in the applied coating was recorded by the industrial camera (Fig. 6) during the entire testing process and determined with the aid of the optical deformation analysis by the measurement software at the end of the test. The evaluation of the test results followed the same principles as the evaluation of the tensile tests' results and was based on the measurement points "P1" to "P4" (Fig. 7a). The measuring points "P5" to "P8" were only used as spare points in case of a crack formation outside of the observed area ("P1-P4"). However, this was not the case for any of the measured samples. The criterion for reaching the maximal strain of the coating was, like in the tensile tests, a crack opening of about $0.2 \mathrm{~mm}$ (hairline crack). Fig. 7 shows an example of the observed area of a coated bending beam in individual steps with time $\mathrm{t}$ and corresponding machine force $F$ during the test. In addition the distances $l_{0}$ at the beginning of the test and $l_{1}$ at the time of a crack opening of $0.2 \mathrm{~mm}$ in the coating were shown.

\subsection{Results}

After evaluating the records of the optical deformation analysis, the results of the maximal strain of the coatings were also summarized for the bending tests and displayed in the form of a bar chart (Fig. 8). Each bar indicates the mean of all samples tested for each coating, and the error bars indicate the standard deviation. Since there were no failures in the bending tests, each coating is represented with all 13 samples in the diagram.

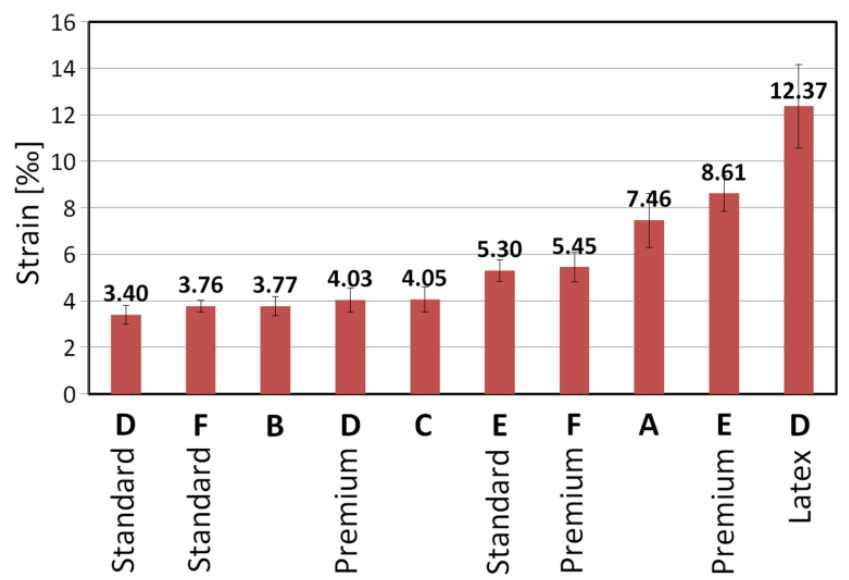

Figure 8: Maximal strain of the interior paints according to the bending tests in \%o.

As can be seen in Fig. 8, the results of the bending tests show that the determined maximal strains comply with the qualitative labels of the coatings tested. For all three manufacturers "D", "E" and "F", of which various products were examined, the "Premium" version shows a significantly better elasticity than the "Standard" version. The "Latex" coating, which was used as a reference dimension for the most ductile of all tested coatings in this study, also achieved the highest value in the results of the bending tests. Its value is $43 \%$ to $264 \%$ higher than the value of the other tested coatings. 


\section{SUMMARY AND DISCUSSION}

The classical tensile test and an innovative bending test were used to quantify the strain of 10 different water-based interior coatings. Using optical deformation analysis, the maximal strain of these coatings up to a crack opening of approx. $0.2 \mathrm{~mm}$ (hairline crack) could be determined with both test methods. The bar chart in Fig. 9 provides an overview of the obtained test results. For each test method, the mean (bar) of the determined maximal strain and the corresponding standard deviation (error bar) of all 10 tested coatings are presented.

As can be seen in Fig. 9, the measured strain of the two test methods used can differ significantly in both absolute and relative terms. It can be concluded that this is not a scaling factor between the two methods, but rather a physical property that affects the measurements. A comparison of the measured values to the qualitative labels of the tested coatings assigned by the manufacturer (Fig. 9) revealed that the strain determined by the bending test shows a higher correlation than the strain determined by the tensile test. Considering the "Latex" coating, which was used as a reference dimension in this study, it should also be noted that the measured strain of this coating achieved the maximum value only in the bending test. One possible reason for these results could be the type of the carrier material which was used for the sample preparation of the tension tests.

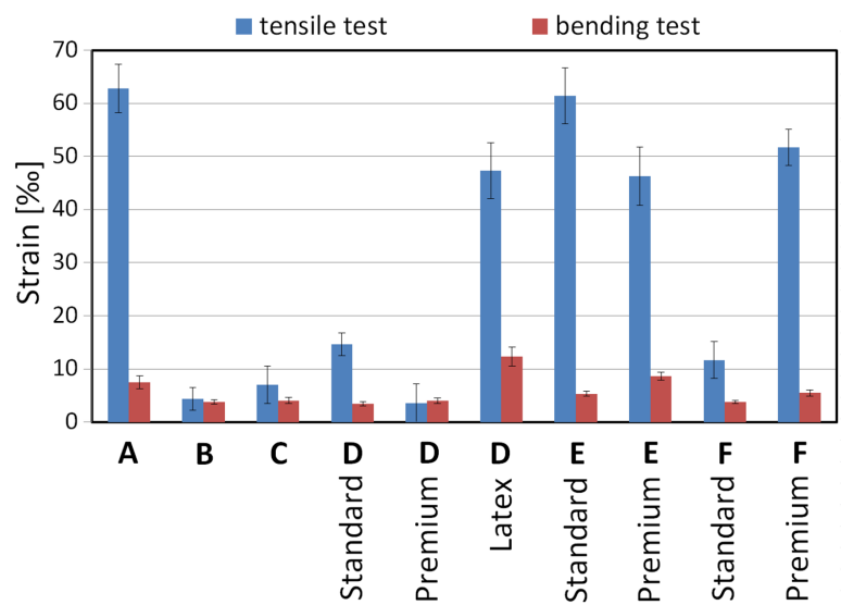

Figure 9: Comparison of the maximal strain of the interior paints according to the tension and the bending tests in \%.

It can be assumed that, through applying the coating on the carton, whose absorbency was much higher than that of the cement bonded particle boards, a kind of impregnation of the carton occurred. Due to the relatively low thickness of the carton of $1 \mathrm{~mm}$, compared to the average thickness of the coating of approx. $0.25 \mathrm{~mm}$ (thickness ratio: 1/4), this impregnation possibly led to a fusion of the mechanical properties of the coating and the carton. As a result, during the tensile tests the extensibility of the applied coating was no longer measured but that of a composite material whose properties differed significantly from those of the coating.

In order to be able to verify whether the used innovative bending test or the classic tensile test is more suitable for strain measurement of interior paints, a verification of the results obtained by both test methods is needed. This can be achieved for example, by using other carrier material for the sample preparation, testing of a coating (material) known strain with both test methods, or using a different test method to determine the strain of the already tested coatings. However, the results of the present study should serve as a basis for any further test method development in the field of strain measurement of interior coatings.

\section{BIBLIOGRAPHY}

[1] HORN, K., GÄNSSMANTEL, J., RISSE: Ursachen, Diagnostik, Instandsetzung (Cracks: Causes, Diagnostic, Repair), Kissing, Germany, WEKA MEDIA GmbH \& Co. KG, (in German), 2017.

[2] MEICHSNER, H., BAUWERKSRISSE kurz und bündig (CONSTRUCTION CRACKS short and precise), Stuttgart, Germany, Fraunhofer IRB Verlag, (in German), 2015.

[3] DIN 18550-1:2017- Design, preparation and application of external rendering and internal plastering - Part 1: Supplementary provisions for DIN EN 13914-1:2016-09 for external rendering, Beuth Verlag, 2017. 
[4] SCHOLZ, D., Typische Baufehler: erkennen - vermeiden - beheben (Common construction failures: identify - prevent repair), Cologne, Germany, Verlagsgesellschaft Rudolf Müller GmbH \& Co. KG, (in German), 2013.

[5] WACHS, P., Schäden an Trockenbaukonstruktionen (Damages to the drywall constructions), Stuttgart, Germany, Fraunhofer IRB Verlag, (in German), 2013.

[6] FRÖSSEL, F., Risse in Gebäuden. Damit aus Fassade kein Ris(s)iko wird (Cracks in buildings. So that the facade does not become a danger), Waldshut-Tiengen, Germany, Baulino Verlag GmbH, (in German), 2009.

[7] KÖNEKE, R., Schäden am Haus. Ursachen - Beseitigung - Kosten (Building damages. Causes - Repairing - Costs), Braunsfeld (Cologne), Germany,Verlagsgesellschaft Rudolf Müller GmbH, (in German), 1985.

[8] DIN EN 1062-7: 2004-08: Paints and varnishes - Coating materials and coating systems for exterior masonry and concrete - Part 7: Determination of crack bridging properties, Beuth Verlag, 2004.

[9] DIN EN 15812: 2011-06: Polymer modified bituminous thick coatings for waterproofing - Determination of crack bridging ability, Beuth Verlag, 2011.

[10] TAN, M.Y.J., ABREU, D., HALLIFAX-BALlingER, T., GREY, B., "An enhanced method for determining the maximum strain a pipeline coating could tolerate”, Progress in Organic Coatings, v. 90, pp. 339-349, 2019.

[11] WRAY, L.A., AYRE, D,. IRVING, P.E., et al. "Implications of Substrate Geometry and Coating Thickness on the Cracking Resistance of Polymer-Based Protective Coatings”, Procedia Structural Integrity, v. 13, pp. 1768-1773, 2018.

[12] ISO 527-1: Plastics - Determination of tensile properties - Part 1: General principles.

[13] DIN EN ISO 6892-1:2017-02: Metallic materials - Tensile testing - Part 1: Method of test at room temperature (ISO 6892-1:2016), Beuth Verlag, 2017.

[14] DIN EN 50125: 2016-12: Testing of metallic materials - Tensile test pieces, Beuth Verlag, 2016.

[15] DIN EN ISO 178: 2013-09: Plastics - Determination of flexural properties (ISO 178:2010 + Amd.1:2013), Beuth Verlag, 2013.

[16] MCELROY, W., Painter's Handbook, Carlsbad, USA, Craftsman Book Company, 2002.

[17] AMERICAN INSTITUTE OF ARCHITECTS, PRESSMAN, A. (ed), Architectural Graphic Standards, 11 ed., Hoboken, USA, John Wiley \& Sons, Inc., 2007.

[18] DIN EN 13300: 2002-11: Paints and varnishes - Water-borne coating materials and coating systems for interior walls and ceilings - Classification, Beuth Verlag, 2002.

[19] ARBEITSKREIS DER SACHVERSTÄNDIGEN IM BAYERISCHEN MALER- UND LACKIERERHANDWERK, Richtlinie zur visuellen Beurteilung beschichteter Oberflächen (Guidelines for evaluating the visual quality of coated surfaces), Stuttgart, Germany, Fraunhofer IRB Verlag, (in German), 2005.

[20] AMBrose, G., HARRIS, P., The Visual Dictionary of Pre-press and Production, Lausanne, Switzerland, AVA Publishing SA, 2010.

[21] AMBROSE, G., HARRIS, P., The Production Manual, 2 ed., London, Bloomsbury Publishing Plc, 2016.

[22] DIN EN 23270: 1991-09: Specification for temperatures and humidities for conditioning and testing paints, varnishes and their raw materials, Beuth Verlag, 2011.

[23] SUTTON, M. A., ORTEU, J. J., SCHREIER, H., Image Correlation for Shape, Motion and Deformation Measurements: Basic Concepts, Theory and Applications, New York, Springer Science \& Business Media, 2009.

[24] SWARD, G. G., “Architectural Paint”, In: SWARD, G. G. (ed), Paint Testing Manual: Physical and Chemical Examination of Paints, Varnishes, Lacquers, and Colors, 13 ed., Lutherville-Timonium, USA, American Society for testing and materials, 1972.

[25] RHARBI, Y., BOUE, F., JOANICOL, M., et al."Structure of stretched latex films", In: Film Formation in Waterbome Coatings, v. 648, ACS Symposium Series, Washington DC: American Chemical Society, pp. 255-270, 1996.

[26] CIDEM Hranice, a.s. - Division CETRIS, cement bonded particleboard - CETRIS® BASIC, http://www.cetris.cz/en/ boards/without-surface-finish/cetris-basic-board/. Accessed in October 2018. 


\section{ORCID}

Aleksandar Milkov Radoevski

https://orcid.org/0000-0002-4155-5622

Michael Höflinger

https://orcid.org/0000-0003-2254-6920

Edmund Spitzenberger

https://orcid.org/0000-0003-2991-2073

Razmik-Roger Ghanbari

https://orcid.org/0000-0002-8709-9378

Andreas Kolbitsch

https://orcid.org/0000-0003-1702-3738 